\title{
Determination of Selected Aromas in Marquette and Frontenac Wine Using Headspace-SPME Coupled with GC-MS and Simultaneous Olfactometry
}

\author{
Somchai Rice ${ }^{1,2,3}$ (D), Nanticha Lutt ${ }^{4}$, Jacek A. Koziel ${ }^{1,2,5, *(\mathbb{D})}$, Murlidhar Dharmadhikari ${ }^{3,5}$ and \\ Anne Fennell ${ }^{6}$ \\ 1 Department of Agricultural and Biosystems Engineering, Iowa State University, Ames, IA 50011, USA; \\ somchai@iastate.edu \\ 2 Interdepartmental Toxicology Graduate Program, Iowa State University, Ames, IA 50011, USA \\ 3 Midwest Grape and Wine Industry Institute, Iowa State University, Ames, IA 50011, USA; murli@iastate.edu \\ 4 Genetics and Plant Biology Program, University of California at Berkeley, Berkeley, CA 94704, USA; \\ nantichalutt@berkeley.edu \\ 5 Department of Food Science and Human Nutrition, Iowa State University, Ames, IA 50011, USA \\ 6 Plant Science Department, South Dakota State University and BioSNTR, Brookings, SD 57007, USA; \\ anne.fennell@sdstate.edu \\ * Correspondence: koziel@iastate.edu; Tel.: +1-515-294-4206
}

Received: 30 December 2017; Accepted: 8 March 2018; Published: 19 March 2018

\begin{abstract}
Understanding the aroma profile of wines made from cold climate grapes is needed to help winemakers produce quality aromatic wines. The current study aimed to add to the very limited knowledge of aroma-imparting compounds in wines made from the lesser-known Frontenac and Marquette cultivars. Headspace solid-phase microextraction (SPME) and gas chromatography-mass spectrometry (GC-MS) with simultaneous olfactometry was used to identify and quantify selected, aroma-imparting volatile organic compounds (VOC) in wines made from grapes harvested at two sugar levels (22 ${ }^{\circ}$ Brix and $24^{\circ}$ Brix). Aroma-imparting compounds were determined by aroma dilution analysis (ADA). Odor activity values (OAV) were also used to aid the selection of aroma-imparting compounds. Principal component analysis and hierarchical clustering analysis indicated that VOCs in wines produced from both sugar levels of Marquette grapes are similar to each other, and more similar to wines produced from Frontenac grapes harvested at $24^{\circ}$ Brix. Selected key aroma compounds in Frontenac and Marquette wines were ethyl hexanoate, ethyl isobutyrate, ethyl octanoate, and ethyl butyrate. OAVs $>1000$ were reported for three aroma compounds that impart fruity aromas to the wines. This study provides evidence that aroma profiles in Frontenac wines can be influenced by timing of harvesting the berries at different Brix. Future research should focus on whether this is because of berry development or accumulation of aroma precursors and sugar due to late summer dehydration. Simultaneous chemical and sensory analyses can be useful for the understanding development of aroma profile perceptions for wines produced from cold-climate grapes.
\end{abstract}

Keywords: aroma dilution analysis; wine; odor activity value; principal component analysis; solid-phase microextraction; GC-MS-Olfactometry

\section{Introduction}

The grape berry undergoes significant changes during ripening, including acid catabolism and the accumulation of sugar, anthocyanins, flavor and aroma compounds [1]. Brix measurements correspond to the percent total soluble solids (TSS), i.e., sugar, in a given weight of grape juice. Sugar content increases throughout berry ripening and is often monitored as a function of maturity. 
Flavor and aroma compounds are complex. Although frequently subjected to sensory analysis, flavor and aroma compounds have limited objective measures specifically identifying the chemical and aroma links. Wines from Albillo and Muscat grape varieties ( $V$. vinifera) have been shown to exhibit more "fruity" aromas and less "vegetal" and "floral" aromas at higher Brix during harvest [2]. Isobutyl methoxypyrazine, C6 alcohols, and hexyl acetate were shown to decrease in wine as Cabernet Sauvignon ( $V$. vinifera) grape maturity developed [3]. The research by Bindon et al. [3] also demonstrated how higher sugar levels led to higher levels of volatile esters, dimethyl sulfide, and glycerol. Many studies have investigated the aroma profile of wines [4-7], with only a few that are focused on cold hardy grapes $V$. labrusca [8] or hybrids of $V$. vinifera, V. labrusca, and V. riparia $[9,10]$. In addition to TSS, $\mathrm{pH}$ and titratable acidity of the grapes is monitored before harvest.

Some varieties of wine have a distinct varietal aroma, and these can be attributed to a few compounds. Examples include 2-methoxy-3-isobutyl pyrazine (a green bell pepper aroma) reported in Sauvignon blanc [11] or 4-vinylguaiacol (spicy, clove aromas) found in Gewurztraminer [12]. Some varieties such as Chardonnay or Seyval do not have characteristic aromas originating from one or two specific compounds $[13,14]$. Understanding the volatile organic compounds (VOCs) that can contribute to the overall aroma profile of wine is important in making high quality, aromatic wines.

Use of solid-phase microextraction (SPME) and GC-MS is common for characterization of VOCs and other compounds in wine $[15,16]$ and food grade alcohols $[17,18]$. VOC partitioning into headspace is suppressed with increasing concentration of ethanol in wine samples; ethanol influenced matrix-VOC partitioning more than glucose levels [19], possibly affecting SPME extraction efficiency of flavor and aroma compounds. SPME is an equilibrium extraction method and if extraction conditions such as extraction temperature, agitation, sampling time can be controlled in the laboratory quantitation using SPME is possible [20]. A previously developed method, optimizing the efficiency of SPME [21], is used in this research.

Aroma dilution analysis (ADA) is helpful in determining the major contributor to the aroma profile of the wine. ADA has been used to evaluate aroma character of Pinot noir grapes [7], Carmenere red wine [22], and Grenache rose wines [23]. It is difficult to dilute extracts while using SPME, so an ADA approach using successive sample dilutions of wine has been demonstrated [24]. Use of SPME in place of ADA has an advantage of speed due to eliminating sample preparation steps. Perceived aroma is not only based on its chemical concentration. Another consideration is the odor detection threshold of a compound (ODT), or the lowest concentration (mass/volume) needed for detection by a human nose [25]. It is critical to recognize that any odor threshold found is valid only at the conditions the test was run. For example, the odor compound will have a different threshold in water, air, and wine and is influenced by environmental conditions during the test. Odor activity value (OAV) is the ratio of the concentration of a compound to its odor detection threshold (ODT), and has been previously discussed [26-29]. It is important to recognize that for the same compound, odor threshold and taste threshold usually have very different values. Recognition thresholds and difference detection thresholds are also used in sensory evaluation of wines, but only ODT is considered in this research.

Frontenac (UMN $89 \times$ Landot 4511) was introduced in 1996 and Marquette $(M N 1094 \times$ Ravat 262) was introduced in 2006 by University of Minnesota. These cold-climate cultivars are of importance because Marquette parentage includes Pinot Noir (grandparent), Cabernet Sauvignon and Merlot (great-great grandparents), Cabernet Franc, and Sauvignon Blanc [30]. Similar aroma profiles are expected between Marquette and Frontenac wines because the cultivars share 25\% parentage from Landot Noir [31,32]. Evaluating the total aroma compounds present in headspace of Frontenac and Marquette wines is important to identify potential varietal aroma character. This information can then be used to compare the aroma of Frontenac and Marquette wines to the more recognizable vinifera wines (Figure 1). 


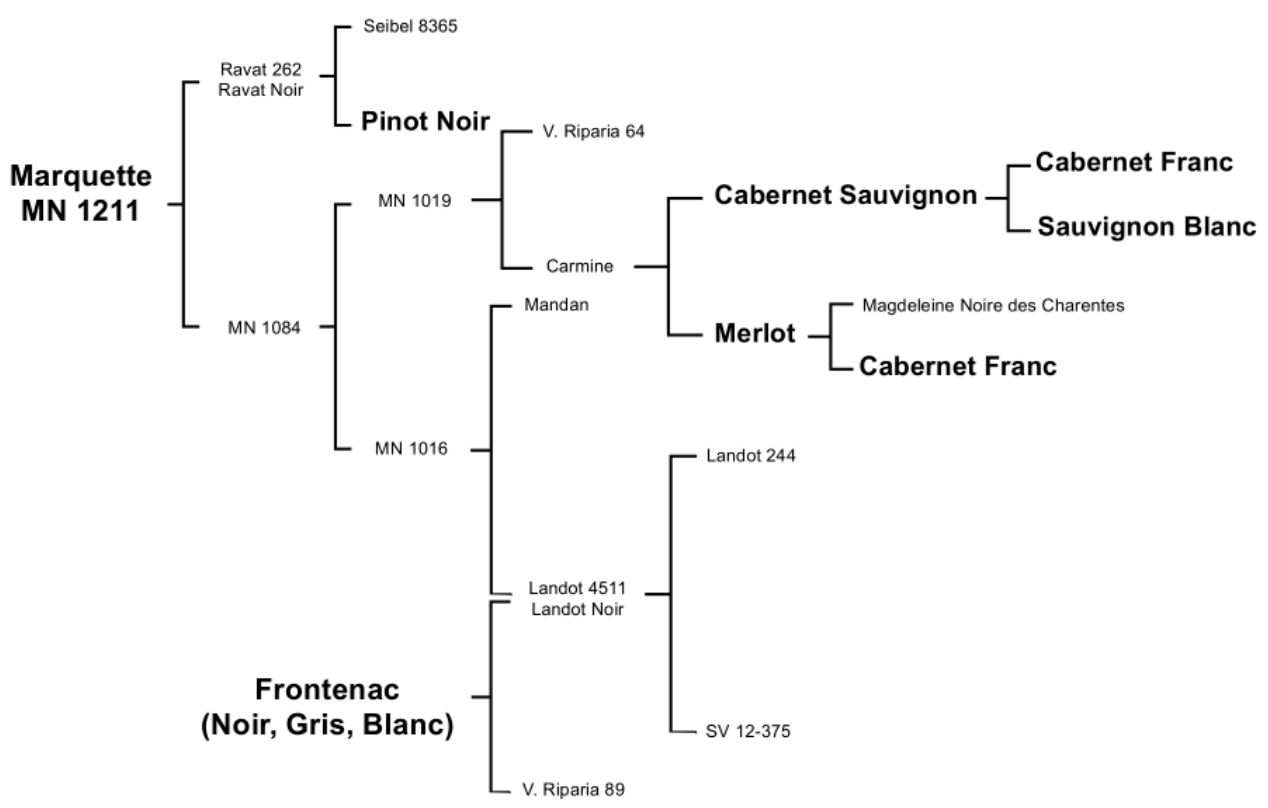

Figure 1. Pedigree of Frontenac and Marquette cultivars. Parentage of Marquette includes Pinot Noir, Cabernet Sauvignon, Merlot, Cabernet Franc, and Sauvignon Blanc. Marquette and Frontenac share common parentage (about 70\%). This figure is adapted from pedigree maps from Chateau Stripmine [31,32].

The objectives of this study were to: (1) determine the relative concentrations of VOCs in the headspace of Marquette and Frontenac wines to an internal standard; (2) perform ADA on the wine samples to characterize the most odorous compounds; and (3) calculate OAV of key aroma compounds. Effects of increased berry "hang time", i.e., the time allowed to remain on the vine before harvest, on wine aroma will help enologists use viticultural practices to enhance desired winemaking styles.

\section{Materials and Methods}

\subsection{Samples, Standards, and Matrix Blank}

Marquette and Frontenac grapes from the 2014 growing season were harvested at $22^{\circ}$ and $24^{\circ}$ Brix at South Dakota State University (Brookings, South Dakota— $44.3114^{\circ} \mathrm{N}, 93.7984^{\circ} \mathrm{W}$ ). The vineyard was part of an NE1020 evaluation trial and was a randomized complete block design. There were four replicates for each cultivar (1 replicate per block with six vines in each replicate). Vines were grown as high cordon in standard NE1020 viticulture protocol. Three clusters were taken from each vine weekly to monitor Brix and for other sample aliquots. All berries were removed from clusters and aliquots were taken from the pool of berries for each replicate. Marquette at $22^{\circ}$ Brix was harvested on 9 September 2013 and $24^{\circ}$ Brix on 21 September 2013. Frontenac at $22^{\circ}$ Brix was harvested on 13 September 2013 and $24^{\circ}$ Brix on 21 September 2013.

A single batch of red wine was made from each harvest time point using the same winemaking protocol. Briefly, 5 gallon fermenters were used for each fermentation, 3 vines from each replicate (12 vines total). Single fermentations were used as the fruit is from the NE1020 coordinated evaluation trial, not a commercial grower.

Wines were produced according to a standard lab protocol at Tucker's Walk Vineyard and Farm Winery (Garretson, SD, USA). Red grapes were mechanically crushed/destemmed, treated with $\mathrm{SO}_{2}$ to $25 \mathrm{ppm}$, and the must inoculated with Pasteur Red (Red star) yeast for fermentation on the skins at $70{ }^{\circ} \mathrm{F}\left(21.1^{\circ} \mathrm{C}\right)$. After 5 days, must was dejuiced and fermentation continued in glass carboys at $70{ }^{\circ} \mathrm{F}$ $\left(21.1^{\circ} \mathrm{C}\right)$ until dry. Malolactic culture was added during the last third of the alcoholic fermentation, as determined by sugar content. 
This wine was shipped to Iowa State University (Ames, IA, USA) for chemical and sensory analysis. Wine samples were aliquoted into $40 \mathrm{~mL}$, pre-cleaned, glass amber vials with a PTFE lined screw cap. These vials were purged with helium to prevent oxidation of the wine samples and stored in a refrigerator before analysis.

A $5 \mathrm{mg} / \mathrm{mL}$ potassium bitartrate in $12.5 \%$ ethanol, $\mathrm{pH} 3.3$ model wine was prepared by dissolving $5 \mathrm{~g}$ of potassium bitartrate (Fischer Scientific, Waltham, MA, USA) in $120 \mathrm{~mL}$ absolute ethanol (Fischer Scientific, Waltham, MA, USA) and q.s. to $1000 \mathrm{~mL}$ with deionized water in a $1000 \mathrm{~mL}$ volumetric flask. The solution was stirred for $10 \mathrm{~min}$ at room temperature, then filtered to remove any solids. The $\mathrm{pH}$ was adjusted with a $3.3 \mathrm{~N}$ hydrogen chloride. This model wine was used for all successive dilutions of wine samples and verified with the analytical method to be a suitable aroma and matrix blank.

For analysis of the undiluted sample, $4 \mathrm{~mL}$ of wine was pipetted into a cleaned $10 \mathrm{~mL}$ glass amber vial with metal screw top lid fitted with a PTFE-lined septum. The $10 \mathrm{~mL}$ vial also contained $2 \mathrm{~g}$ of sodium chloride, CAS 7440-23-5 (Sigma-Aldrich, St. Louis, MO, USA). 3-nonanone (99\%), CAS 925-78-0 (Sigma-Aldrich, St. Louis, MO, USA), was used as an internal standard (IS) for semi-quantification of aroma compounds. The final concentration of IS in wine $(0.205 \mathrm{mg} / \mathrm{L})$ was achieved by adding $10 \mu \mathrm{L}$ of an $81.9 \mathrm{mg} / \mathrm{L}$ IS in ethanol $(w / v)$ to each $4 \mathrm{~mL}$ of wine. Triplicate samples were analyzed.

\subsection{Aroma Dilution Analysis}

A simple ADA was performed by analyzing successive dilutions of the wine sample, until the odor response from each compound or chromatographic column elution time region of interest was no longer noted at the olfactory detector. The odor dilution (OD) was assigned to the value of the sample dilution that results in odor extinction (i.e., not detected) at the olfactory detector (sniff port of GC). The higher the OD, the more significant that compound was in the overall aroma profile of the sample. Triplicate samples were analyzed, by a single trained panelist. Table 1 outlines dilution factors and weighting factors used in this research.

Table 1. Dilution and weighting factors of successive wine sample dilutions used in headspace solid phase microextraction gas chromatography-mass spectrometry-olfactometry (HS-SPME GC-MS-O) aroma dilution analysis.

\begin{tabular}{ccccc}
\hline Dilution Factor & Weighting Factor & $\begin{array}{c}\text { Sample } \\
\text { Volume }(\mathbf{m L})\end{array}$ & $\begin{array}{c}\text { Model Wine } \\
\text { Volume }(\mathbf{m L})\end{array}$ & $\begin{array}{c}\text { Total Volume } \\
(\mathbf{m L})\end{array}$ \\
\hline 0 & 1.000 & 4.000 & 0.000 & 4 \\
2 & 0.500 & 2.000 & 2.000 & 4 \\
4 & 0.250 & 1.000 & 3.000 & 4 \\
8 & 0.125 & 0.500 & 3.500 & 4 \\
16 & 0.063 & 0.250 & 3.750 & 4 \\
32 & 0.031 & 0.125 & 3.875 & 4 \\
\hline
\end{tabular}

\subsection{Automated GC-MS-Olfactometry System}

A CTC CombiPal ${ }^{\mathrm{TM}}$ autosampler with a heated agitator (LEAP Technologies, Inc., Carrboro, NC, USA) was used during the entire experiment. The optimized sampling parameters are described

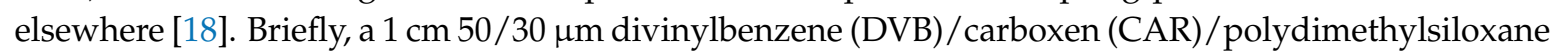
(PDMS) SPME was used for headspace sampling. Extraction time was $10 \mathrm{~min}$ at $50^{\circ} \mathrm{C}$, after $10 \mathrm{~min}$ incubation at $50^{\circ} \mathrm{C}$. Agitation speed was $500 \mathrm{rpm}$. The fiber was thermally desorbed in a $260^{\circ} \mathrm{C} \mathrm{GC}$ inlet for $2 \mathrm{~min}$ before exposure in sample headspace. Analytes were desorbed into the GC inlet for 2 min at $260{ }^{\circ} \mathrm{C}$.

The analysis was performed on a $6890 \mathrm{~N}$ GC/5973 Network mass spectrometer (Agilent Technologies, Santa Clara, CA, USA). The instrument allowed for heartcutting with a Dean's switch, cryogenic focusing, and was equipped with a FID and an olfactometry port. The GC contains two columns connected in series. The first non-polar column was a BPX-5 stationary phase with dimensions 
$30 \mathrm{~m}$ length $\times 0.53 \mathrm{~mm}$ ID $\times 0.5 \mu \mathrm{m}$ film thickness (SGE, Austin, TX, USA). The second polar column was SOLGEL-Wax stationary phase with dimensions of $30 \mathrm{~m}$ length $\times 0.53 \mathrm{~mm}$ ID $\times 0.5 \mu \mathrm{m}$ film thickness (SGE, Austin, TX, USA). A constant pressure of 5.7 psi was maintained at the midpoint between the first and second column using MultiTrax ${ }^{\mathrm{TM}}$ V.10.1 (MOCON, Round Rock, TX, USA) system automation and MSD ChemStation ${ }^{\mathrm{TM}}$ D.02.02.275 data acquisition software (Agilent, Santa Clara, CA, USA). Additional analysis was done using MassHunter Workstation (Agilent, Santa Clara, CA, USA) with NIST11 mass spectral database and BenchTop/PBM with Wiley Registry of mass spectral data, 7th edition (Palisade Corporation, New York, NY, USA). Flow from the analytical column was directed to the single quadrupole mass selective detector and the olfactometry port in an open-split interface via fixed restrictor tubing.

For this research, full heartcut was utilized from 0.05 to $35.00 \mathrm{~min}$. An advantage of using two-dimensional gas chromatography is that separation is based on different and independent physico-chemical interactions (i.e., boiling point on the first column vs. polarity on the second column) for the entire chromatographic run. This serves as a fast screening method for VOCs, and can help select target VOCs for subsequent analysis. Sample flow was first directed through the non-polar column, then immediately to the polar column, therefore known retention indices for either column phase were used for identification. The following instrument parameters were used: injector, $260{ }^{\circ} \mathrm{C}$; column, $40^{\circ} \mathrm{C}$ initial, $3.0 \mathrm{~min}$ hold, $7^{\circ} \mathrm{C} / \mathrm{min}$ ramp, $220^{\circ} \mathrm{C}$ final, $11.29 \mathrm{~min}$ hold; carrier gas, UHP helium (99.999\%) with combination oxygen and moisture in-line gas trap. The mass detector was operated in electron ionization (EI) mode with an ionization energy of $70 \mathrm{eV}$. The mass detector ion source and quadrupole were held at $230{ }^{\circ} \mathrm{C}$ and $150{ }^{\circ} \mathrm{C}$, respectively. Full spectrum scans were collected with the mass filter set from $m / z 33$ to $m / z$ 450. The MS was auto-tuned daily before analysis. Use of full scan for data acquisition allowed for library search techniques using NIST11, and Wiley 6th edition mass spectral databases, and AMDIS with the accompanying food and flavor targeted mass spectral library.

Olfactometry data were generated using AromaTrax ${ }^{\mathrm{TM}}$ V.10.1 software (MOCON, Round Rock, TX, USA). Recorded parameters included an aroma descriptor ("note") and perceived intensity. The area under the peak of each aroma note in the aromagram is calculated as width $\times$ intensity $\times 100$, where the width is the length of time (min) that the aroma persisted, in minutes. ADA was performed by analyzing successive dilutions of the same sample on the AromaTrax system V 10.1 (MOCON, Round Rock, TX, USA). The results files created have information about each aroma note such as elution time, intensity, and aroma descriptors. This information was combined into an ADA aromagram using a dilution and intensity weighting model. In this model, each peak in the results files that match a peak in the master file (Dilution Factor 0-Neat) is added to the ADA file based upon the intensity, multiplied by the dilution factor. For example, for a peak found in all 5 dilutions with intensities 90 , $75,45,35,5$ and dilution factors of $1 / 2,1 / 4,1 / 8,1 / 16,1 / 32$, the final intensity would be: $(90 \times 0.5)+$ $(75 \times 0.25)+(45 \times 0.125)+(35 \times 0.063)+(5 \times 0.031)=72$. These values were then plotted in an analog manner, with \% full-scale intensity vs. time.

\section{Results}

\subsection{Semi-Quantitative Analysis of Volatiles in Wine}

Ethanol was present in all samples, including the matrix blank (model wine). The chromatographic peak at RT $3.9 \mathrm{~min}$ is ethanol in all total ion chromatograms (TIC). Since ethanol is present in all samples, it is not included in the further discussion. The signal-to-noise ratio of total ion chromatograms of $\geq 10$ was considered acceptable. Percent spectral match of sample spectra to library spectra was acceptable at $65 \%$ or higher.

58 unique VOCs are detected in the headspace of Marquette and Frontenac wines produced from grapes harvested at $22^{\circ}$ and $24^{\circ}$ Brix (Table 2). Compounds including isoamyl alcohol, ethyl octanoate, 2,4-di-tert-butylphenol, ethyl acetate, ethyl hexanoate, ethyl decanoate, isocyanatomethane, and ethyl 
lactate are present in wine samples at higher concentrations relative to $0.205 \mathrm{ppm}$ of 3-nonanone IS and assuming equal detector response for all analytes. A full summary of retention times, published aroma descriptors, and relative concentrations of these 58 analytes detected in all samples are given in the Supplementary Materials, Table S1.

Table 2. Compounds identified in the headspace of Marquette and Frontenac wines using AMDIS and a lab developed mass spectral library.

\begin{tabular}{|c|c|c|}
\hline No. & Compound & Relative Retention $^{1}$ \\
\hline 1 & Acetaldehyde & 0.18 \\
\hline 2 & Methyl acetate & 0.22 \\
\hline 3 & 2-nitropropane & 0.22 \\
\hline 4 & Isobutyraldehyde & 0.22 \\
\hline 5 & Ethanol & 0.25 \\
\hline 6 & Ethyl acetate & 0.27 \\
\hline 7 & Acetic acid ethenyl ester & 0.30 \\
\hline 8 & Methylbutanal & 0.31 \\
\hline 9 & 1,1-dimethyl-hydrazine & 0.33 \\
\hline 10 & $n$-Propyl acetate & 0.38 \\
\hline 11 & Isobutanol & 0.39 \\
\hline 12 & Ethyl isobutyrate & 0.42 \\
\hline 13 & 1-butanol & 0.46 \\
\hline 14 & Isobutyl acetate & 0.46 \\
\hline 15 & Ethyl butyrate & 0.51 \\
\hline 16 & Isoamyl alcohol & 0.54 \\
\hline 17 & 3-methylpentane & 0.55 \\
\hline 18 & Isocyanatomethane & 0.55 \\
\hline 19 & Ethyl methylbutyrate & 0.58 \\
\hline 20 & Ethyl 3-methylbutanoate & 0.59 \\
\hline 21 & Isoamyl acetate & 0.65 \\
\hline 22 & Ethyl lactate & 0.72 \\
\hline 23 & Styrene & 0.73 \\
\hline 24 & 1-hexanol & 0.76 \\
\hline 25 & Acetic acid & 0.79 \\
\hline 26 & 1,2-dimethyl hydrazine & 0.79 \\
\hline 27 & Ethyl hexanoate & 0.85 \\
\hline 28 & 1-Heptanol & 0.92 \\
\hline 29 & 2,3,4-trimethylpentane & 0.94 \\
\hline 30 & Isoamyl butyrate & 0.94 \\
\hline 31 & Undecane & 0.97 \\
\hline 32 & Benzaldehyde & 0.97 \\
\hline 33 & 3-Nonanone (IS) & 1.00 \\
\hline 34 & Methyl octanoate & 1.06 \\
\hline 35 & 1-Octanol & 1.06 \\
\hline 36 & Octyl formate & 1.06 \\
\hline 37 & Linalool & 1.08 \\
\hline 38 & Phenylethanal & 1.11 \\
\hline 39 & Ethyl octanoate & 1.16 \\
\hline 40 & 1-Nonanol & 1.20 \\
\hline 41 & Pentanoic acid & 1.25 \\
\hline 42 & Propyl octanoate & 1.28 \\
\hline 43 & Ethyl nonanoate & 1.30 \\
\hline 44 & Methyl salicylate & 1.30 \\
\hline 45 & Methyl acetylsalicylate & 1.30 \\
\hline 46 & Phenylethyl alcohol & 1.34 \\
\hline 47 & Phenethyl isobutyrate & 1.37 \\
\hline 48 & Phenethyl phenyl acetate & 1.37 \\
\hline 49 & Ethyl decanoate & 1.42 \\
\hline 50 & Octanoic Acid & 1.47 \\
\hline 51 & $\beta$-damascenone & 1.47 \\
\hline 52 & Isoamyl octanoate & 1.49 \\
\hline 53 & Ethyl laurate & 1.66 \\
\hline 54 & 2,4-di-tert-butylphenol & 1.76 \\
\hline 55 & Diethyl phthalate & 1.85 \\
\hline 56 & Ethyl tetradecanoate & 1.89 \\
\hline 57 & Ethyl hexadecanoate & 2.14 \\
\hline 58 & Dibutyl phthalate & 2.37 \\
\hline
\end{tabular}

${ }^{1}$ Relative retention is the ratio of the compound retention time to the retention time of the internal standard 3-nonanone, in minutes.

Principal component analysis (PCA) was performed on the 58 VOCs found in all wine samples (Figure 2). Please refer to Table 2 for compound identification. Wine produced from Frontenac berries harvested at $22^{\circ}$ Brix (F22-1, F22-2, and F22-3) is associated with higher levels of 1-octanol (compound 35), ethyl laurate (compound 53), methylbutanal (compound 8), undecane (compound 31), and ethyl 
tetradecanoate (compound 56). Wine produced from Frontenac berries harvested at $24^{\circ}$ Brix (F24-1, F24-2, and F24-3) is associated with higher levels of ethyl isobutyrate, ethyl-3-methylbutanoate, ethyl lactate, and 1-hexanol. Wine produced from Marquette berries harvested at $22^{\circ}$ Brix (M22-1, M22-2, and M22-3) is associated with higher levels of acetaldehyde, ethyl butyrate, 1-hexanol, isoamyl butyrate, and 1-nonanal. Wine produced from Marquette berries harvested at $24^{\circ}$ Brix (M24-1, M24-2, and M24-3) is associated with higher levels of ethyl hexanoate, propyl octanoate, and isobutyl acetate.

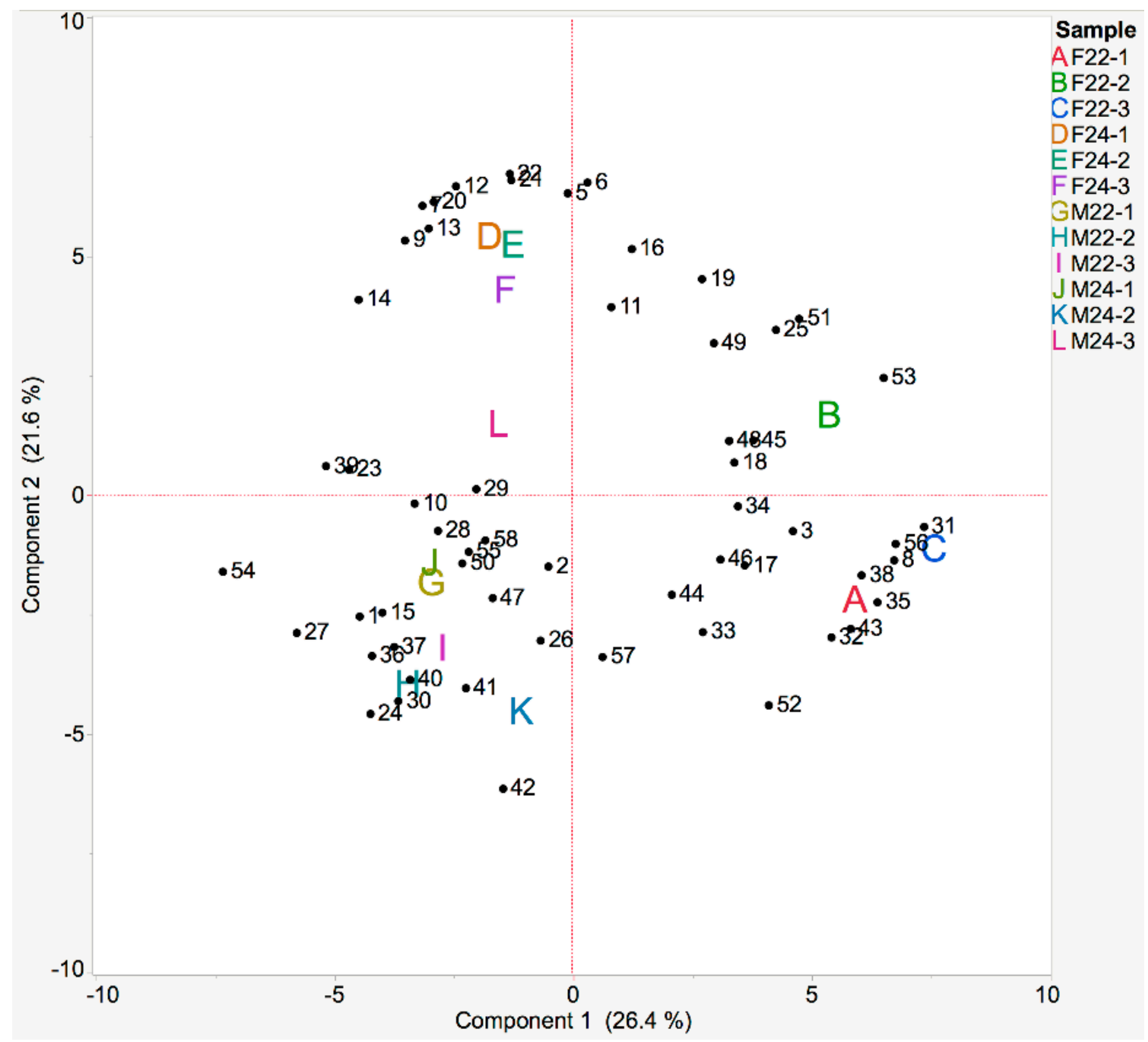

Figure 2. Results of a PCA on wines produced from Frontenac and Marquette berries harvested at 24 and $24^{\circ}$ Brix. This biplot shows both the relationships of the wines to each other and the associations among the VOCs detected in the headspace. Vector arrows of the VOCs are not shown, but can be assumed to originate from the origin and ending at the numbered markers. The numbered markers indicate the compound identified, and are listed in Table 2. An example of sample naming convention is F22-1 used to represent wines produced from Frontenac berries, harvested at $22^{\circ}$ Brix, analysis replicate 1.

A hierarchical cluster analysis was performed to identify the grouping of wine samples based on the degree of similarity in aroma compounds in headspace, and the constellation plot is shown in Figure 3. The cluster containing wine made from Frontenac berries harvested a $22^{\circ}$ Brix is the most dissimilar to the other clusters representing the rest of the wines. 


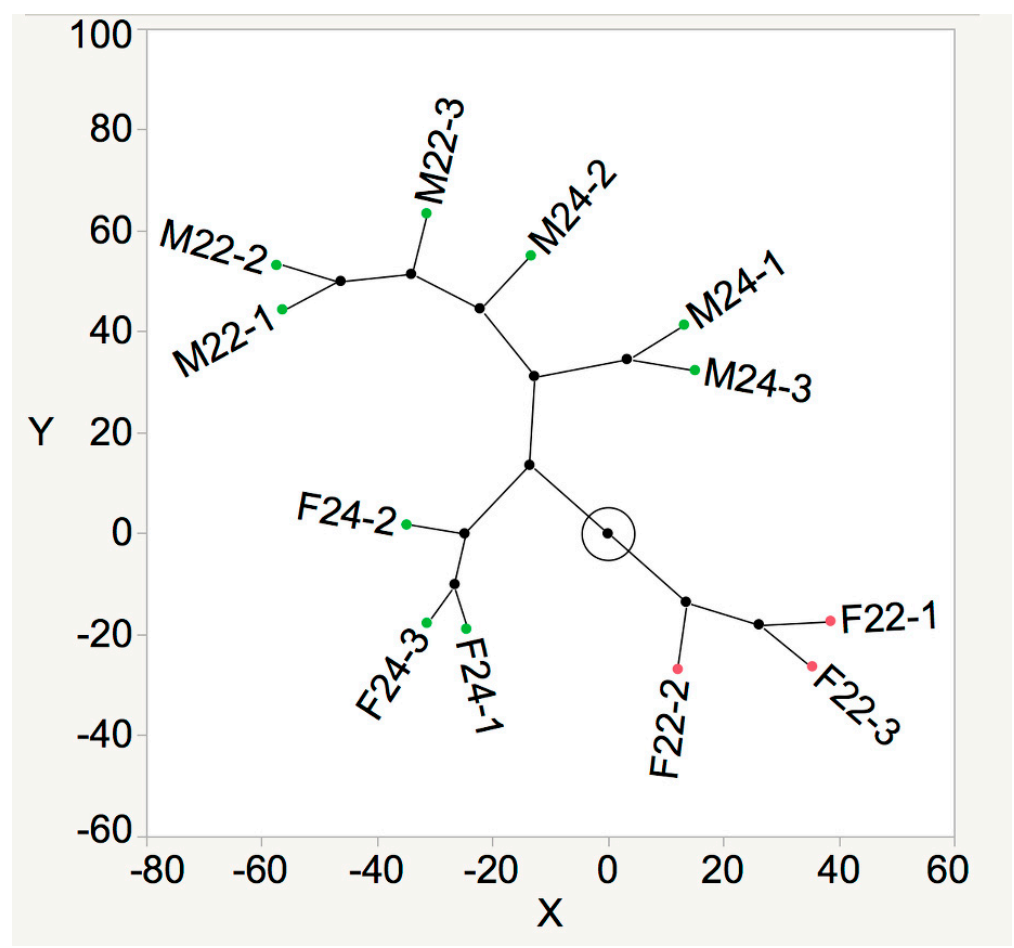

Figure 3. A constellation plot showing similarities in aroma compounds in Marquette and Frontenac wines produced from berries harvested at $22^{\circ}$ and $24^{\circ}$ Brix. The wine samples are arranged as endpoints and each cluster joins as a new point, with lines drawn representing membership. The longer the line, the greater the difference.

\subsection{Aroma Dilution Analysis}

Results of the full scan total ion chromatogram (TIC) for each $4 \mathrm{~mL}$ sample of wine was overlaid with the panelist generated aromagram (Supplementary Materials, Figures S1-S4). Olfactometry results including aroma descriptors, intensity, GC column retention time, and aroma event ("peak") areas were collected simultaneously with chemical analysis (Tables S1-S5). There were 15, 6, 7, and 7 aroma notes found in wines made from $22^{\circ}$ Brix Frontenac, $24^{\circ}$ Brix Frontenac, $22^{\circ}$ Brix Marquette, and $24^{\circ}$ Brix Marquette, respectively. These results were used as the master results to compare aromas from the diluted samples.

Each wine sample was diluted and analyzed again with the same methodology using dilution factors of 2, 4, 8, 16, and 32. The OD of each aroma event (detection) corresponds to the dilution of the wine in which the event was no longer present (not detected). The compound with the highest OD was contributing significantly more to the total aroma profile of the wine. After weighing the aroma notes by the dilution factor and intensities, these new values were shown in an ADA plot.

Marquette wine made from grapes harvested at $22^{\circ}$ Brix had 14 aroma notes (excluding ethanol at $3.9 \mathrm{~min}$ ) in the undiluted sample. After ADA (Figure 4), two events were calculated and identified as the most impactful to the total aroma profile of the wine: (1) $13.3 \mathrm{~min}, \mathrm{OD} 8$; and (2) $6.6 \mathrm{~min}, \mathrm{OD}$ 2. The event at $3.9 \mathrm{~min}$ is ethanol, present in all samples, and therefore not included in the further discussion. These two aroma events corresponded to retention times of compounds simultaneously identified by mass spectrometer: (1) ethyl hexanoate; and (2) ethyl isobutyrate. 


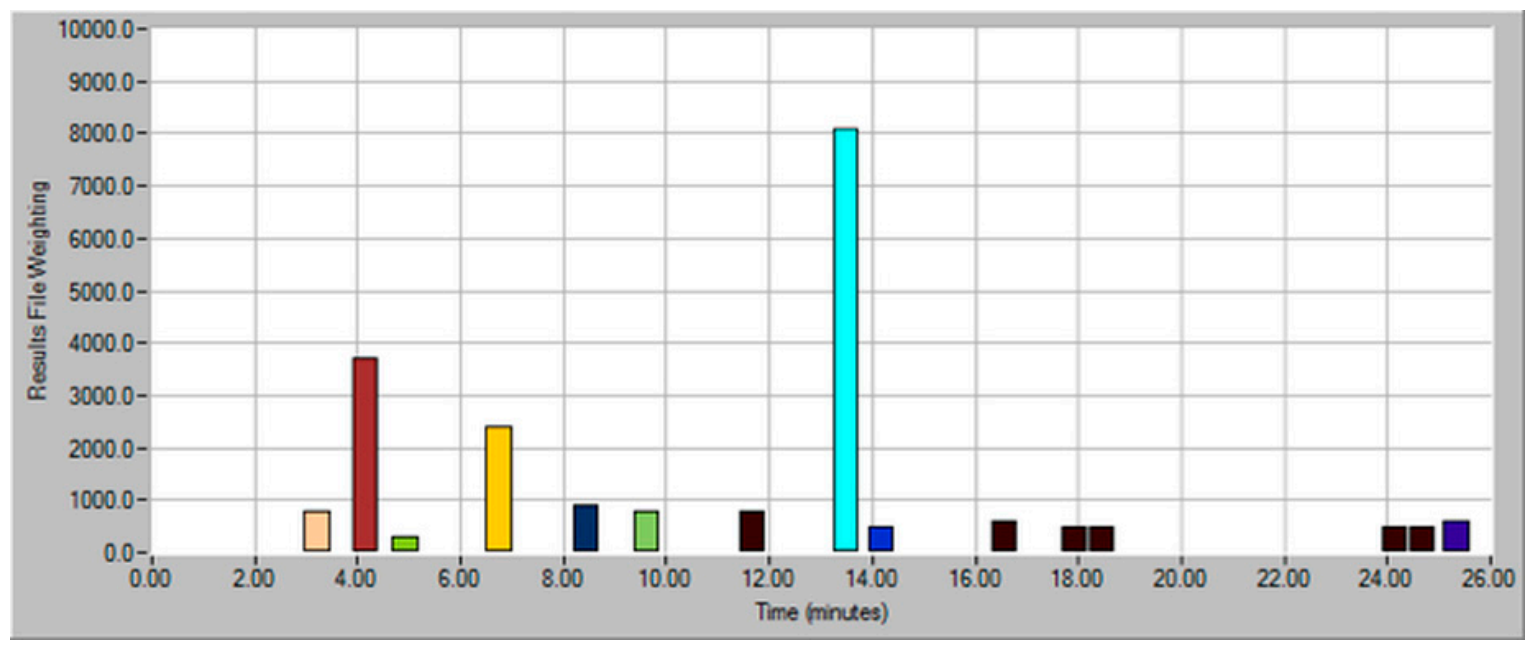

Figure 4. Aroma dilution analysis plot of wine made from Marquette grapes harvested at $22^{\circ}$ Brix. The compound most impactful in the total aroma of this sample occurred at 13.3 min (light blue bar), assigned odor dilution number 8 , and simultaneously identified using a mass spectrometer as ethyl hexanoate.

Marquette wine made from grapes harvested at $24^{\circ}$ Brix had five aroma notes (excluding ethanol at $3.9 \mathrm{~min}$ ) in the undiluted sample. After ADA (Figure 5), two events were calculated to be most impactful to the total aroma profile of the wine: (1) $22.0 \mathrm{~min}$, OD 8 and (2) $8.3 \mathrm{~min}$, OD 2. These two aroma events correspond to retention times of compounds simultaneously identified by mass spectrometer: (1) ethyl decanoate; and (2) ethyl butyrate.

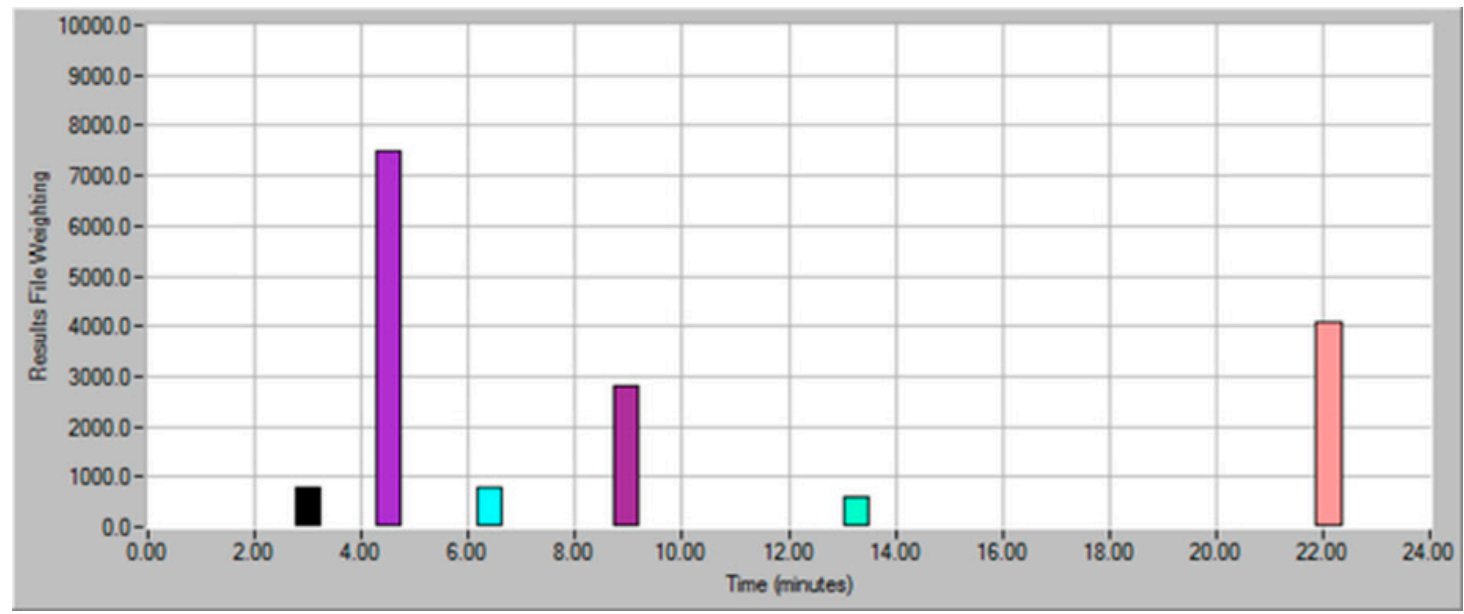

Figure 5. Aroma dilution analysis plot of wine made from Marquette grapes harvested at $24^{\circ}$ Brix. The compounds most impactful in the total aroma of this sample occurred at: (1) $22.0 \mathrm{~min}$, assigned odor dilution number 8; and (2) $8.3 \mathrm{~min}$, assigned odor dilution number 2, while simultaneously identified using a mass spectrometer as: (1) ethyl decanoate; and (2) ethyl butyrate.

Frontenac wine made from grapes harvested at $22^{\circ}$ Brix had six aroma notes (excluding ethanol at $3.9 \mathrm{~min}$ ) in the undiluted sample. After ADA (Figure 6), two events were calculated to be most impactful to the total aroma profile of the wine: (1) $13.3 \mathrm{~min}$, OD 16; and (2) $18.0 \mathrm{~min}$, OD 16. These two aroma events correspond to retention times of compounds simultaneously identified by mass spectrometer: (1) ethyl hexanoate; and (2) ethyl octanoate. 


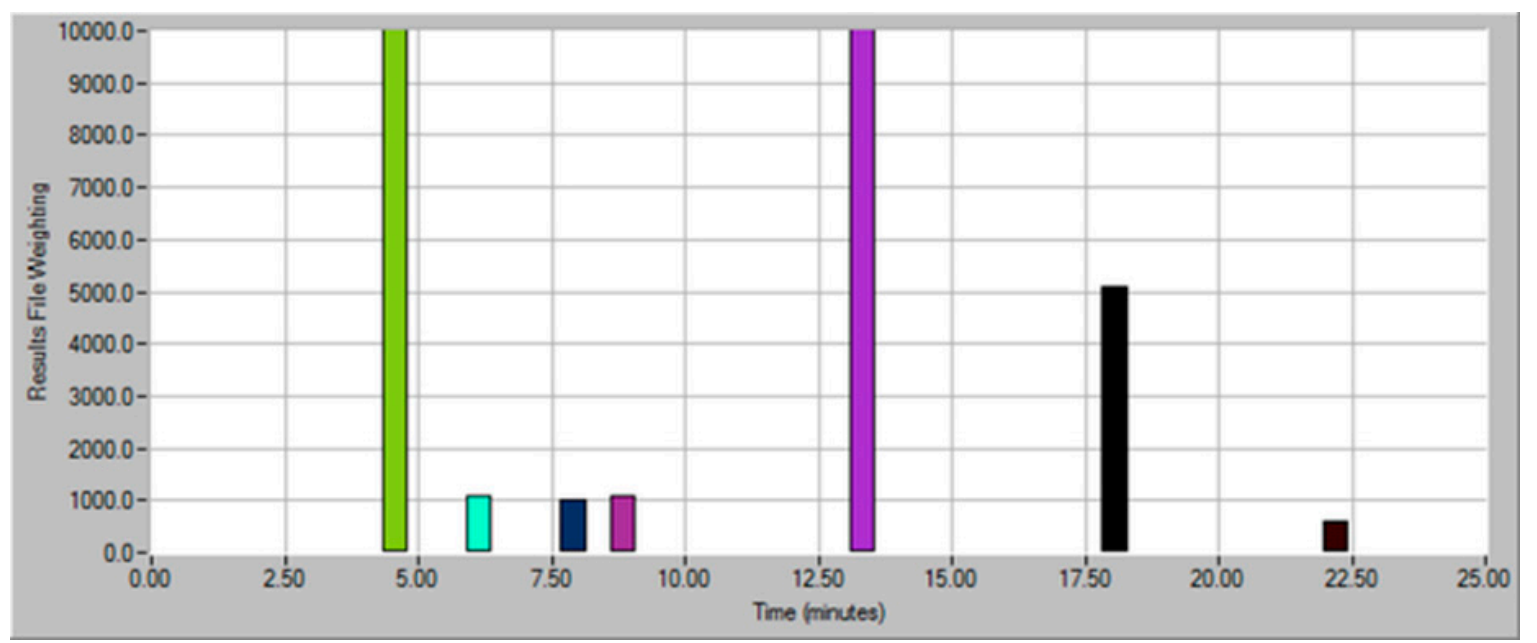

Figure 6. Aroma dilution analysis plot of wine made from Frontenac grapes harvested at $22^{\circ}$ Brix. The compounds most impactful in the total aroma of this sample occurred at: (1) 13.3 min, assigned odor dilution number 16; and (2) $18.0 \mathrm{~min}$, assigned odor dilution number 16, while simultaneously identified using a mass spectrometer as: (1) ethyl hexanoate; and (2) ethyl octanoate.

Frontenac wine made from grapes harvested at $24^{\circ}$ Brix had six aroma notes (excluding ethanol at $3.9 \mathrm{~min}$ ) in the undiluted sample. After ADA (Figure 7), four events were calculated to be most impactful to the total aroma profile of the wine: (1) $18.0 \mathrm{~min}$, OD 8; (2) $22.3 \mathrm{~min}$, OD 8; (3) $8.6 \mathrm{~min}$, OD 4; and (4) $6.3 \mathrm{~min}$, OD 4. These four aroma events correspond to retention times of compounds simultaneously identified by mass spectrometer: (1) ethyl octanoate; (2) ethyl decanoate; (3) 1-pentanol; and (4) ethyl isobutyrate. Ethyl butyrate was also present but not discussed because OD $=1$ for this event. The aroma event at $13.0 \mathrm{~min}$ also had an $\mathrm{OD}=1$ and was not detected by the mass spectrometer. It is possible that not enough mass of analyte was directed to the mass spectrometer at retention time $13.0 \mathrm{~min}$, via the open-split interface to sniff port, and therefore did not generate a chemical signal. It is likely that this compound has a very low ODT, and the human nose was a better detector for this compound.

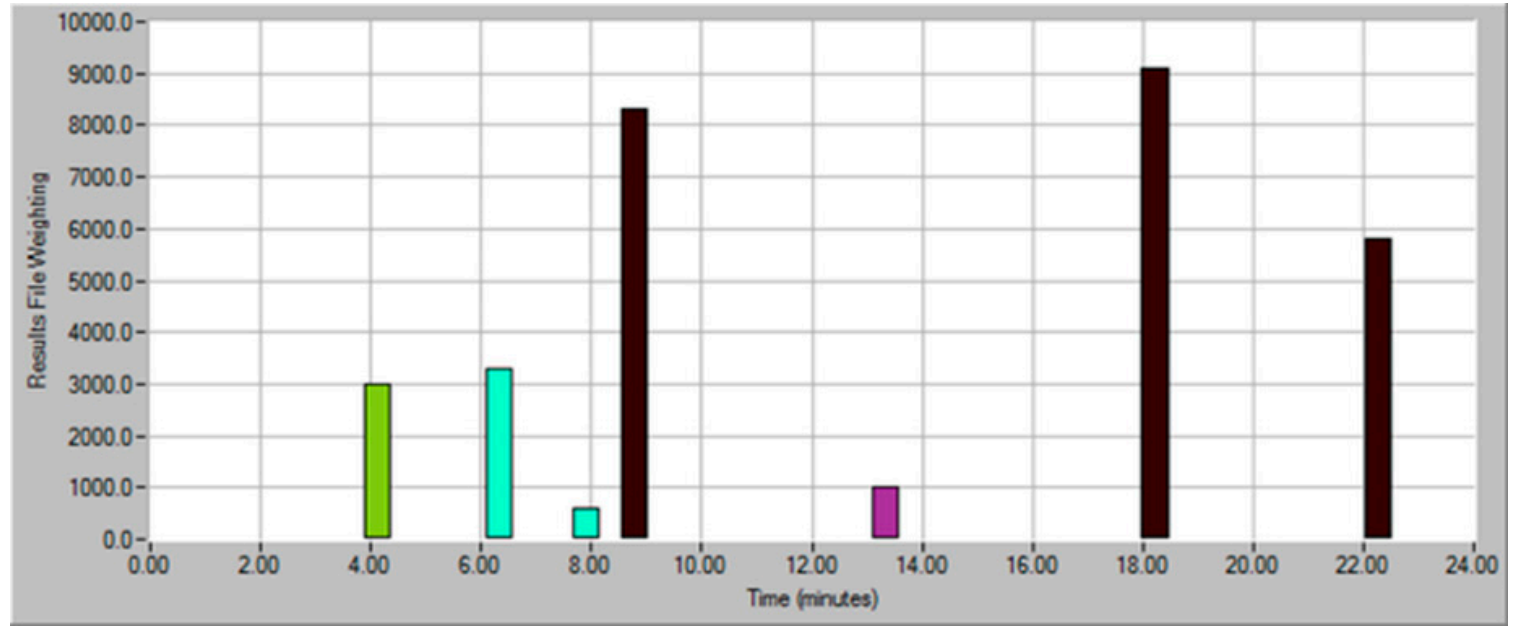

Figure 7. Aroma dilution analysis plot of wine made from Frontenac grapes harvested at $24^{\circ}$ Brix. The compounds most impactful in the total aroma of this sample occurred at: (1) $18.0 \mathrm{~min}$, assigned odor dilution number 8; (2) $22.3 \mathrm{~min}$, assigned odor dilution number 8; (3) $8.6 \mathrm{~min}$, assigned odor dilution number 4; and (4) $6.3 \mathrm{~min}$, assigned odor dilution number 4, while simultaneously identified using a mass spectrometer as: (1) ethyl octanoate; (2) ethyl decanoate; (3) 1-pentanol; and (4) ethyl isobutyrate. 
Five compounds are identified as key aromas in Marquette and Frontenac wine samples from ADA. These compounds are ethyl butyrate, ethyl decanoate, ethyl hexanoate, ethyl isobutyrate, and ethyl hexanoate. Concentrations of the five compounds in wine samples are calculated by external calibration. Quantitation range and coefficients of determination $\left(R^{2}\right)$ from the linear model are given in Table 3. Ethyl butyrate and ethyl decanoate concentrations are lower than the quantitation limit for this method. Calculated concentrations of ethyl hexanoate, ethyl isobutyrate, and ethyl octanoate in Frontenac and Marquette wines produced from berries harvested at $22^{\circ}$ and $24^{\circ}$ Brix are summarized in Figure 8. Generally, these compounds have decreased concentrations in the headspace of wine samples as sugar content of the grapes at harvest increased. Marquette wines had higher concentrations of ethyl hexanoate $(9.5$ and $1.3 \mathrm{ppm})$, ethyl isobutyrate (0.7 and $0.5 \mathrm{ppm})$, and ethyl octanoate (41.9 and 17.9 ppm). Analyte concentrations in Frontenac wines were $1.3 \mathrm{ppm}$ (not detected in wine produced from $24^{\circ}$ Brix) of ethyl hexanoate, $0.5 \mathrm{ppm}$ of ethyl isobutyrate, and 21.5 and $15.6 \mathrm{ppm}$ of ethyl octanoate.

Table 3. Quantitation range and linear coefficients of determination for 5 key aroma compounds in wine.

\begin{tabular}{ccc}
\hline Compound & Quantitation Range $(\mathbf{p p m})$ & $\mathbf{R}^{\mathbf{2}}$ \\
\hline Ethyl hexanoate & $2.89 \times 10^{-2}-1.16 \times 10^{2}$ & 0.998 \\
Ethyl isobutyrate & $2.86 \times 10^{-2}-1.15 \times 10^{2}$ & 0.999 \\
Ethyl octanoate & $2.88 \times 10^{-2}-1.15 \times 10^{2}$ & 0.998 \\
Ethyl decanoate & $2.79 \times 10^{-2}-1.12 \times 10^{2}$ & 0.997 \\
Ethyl butyrate & $2.93 \times 10^{-2}-1.17 \times 10^{2}$ & 0.999 \\
\hline
\end{tabular}

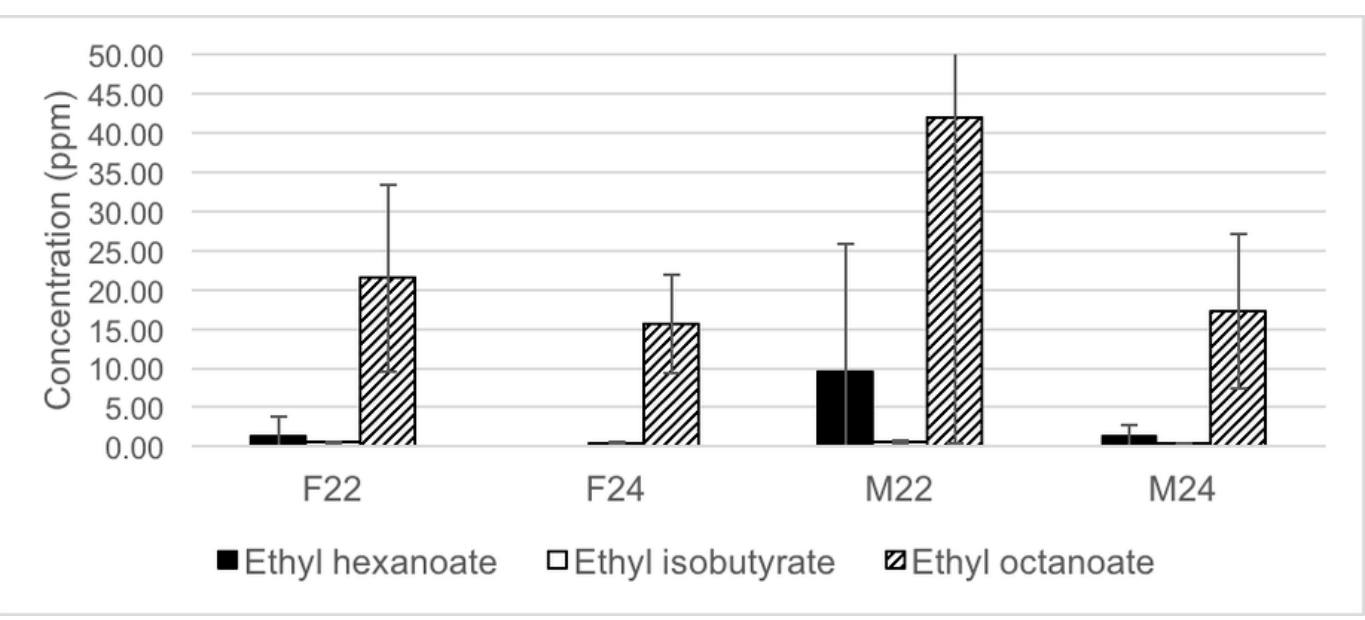

Figure 8. Concentrations of target analytes in headspace of Marquette and Frontenac wines made from berries harvested at $22^{\circ}$ and $24^{\circ}$ Brix. A five-point external calibration was performed using standards spiked into model wine. Data represent the mean of replicate analysis $(n=3)$ of each wine produced. F22 represents Frontenac wine produced from berries harvested at $22^{\circ}$ Brix, F24 represents Frontenac wine produced from berries harvested at $24^{\circ}$ Brix, etc.

\subsection{Calculation of $O A V$}

The OAV of the three quantified compounds are calculated from published odor detection thresholds and are reported as $>1000$ (Figure 9). The key aroma compounds impart fruity characters to the wines as determined by a single human panelist. The dominant aroma compound in all wine samples of this study is ethyl isobutyrate $(\mathrm{OAV}>50,000)$, which imparts a fruity aroma. 


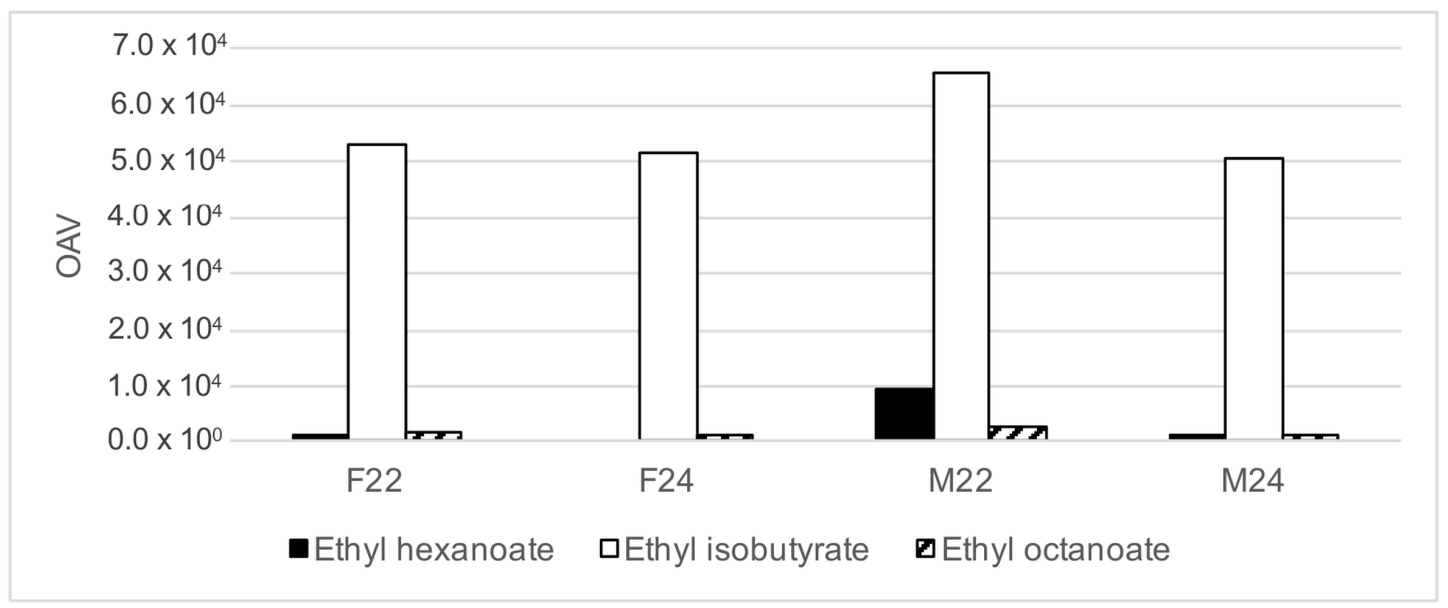

Figure 9. Odor (aroma) activity values of target analytes in headspace of Marquette and Frontenac wines made from berries harvested at $22^{\circ}$ and $24^{\circ}$ Brix. Odor detection thresholds for each analyte in water (and wine when available) from Leffingwell and Associates [33] were used to calculate OAV. OAV is the ratio of analyte concentration to its odor detection threshold. Ethyl octanoate is the dominate aroma compound present in headspace of Marquette and Frontenac wine samples (excluding alcohol), followed by ethyl hexanoate and ethyl octanoate. These compounds impart fruity aromas to the wine samples.

\section{Discussion and Conclusions}

In this research, headspace sampling using SPME, GC-MS and simultaneous olfactometry was used to investigate the key volatile aroma compounds in Frontenac and Marquette wines harvested at two maturity time points. ADA was performed to determine the key compounds present in these wine samples, and detected by human nose. Fifty-eight VOCs were detected in headspace of wines made from Frontenac and Marquette grapes harvested at $22^{\circ}$ and $24^{\circ}$ Brix by GC-MS, excluding ethanol and IS. In this study, the use of an internal standard was used to estimate relative chromatographic retention time and relative concentrations, assuming equal response factor across all analytes. A range of VOCs was detected by mass spectrometry including 9 alcohols, 5 aldehydes, 5 alkanes, 29 esters, 2 each of ketones, nitrogenous compounds, phenolic compounds and others. Yeast metabolism produces important wine volatiles such as higher alcohols, fatty acids, esters, and aldehydes. The reported results correspond to expected VOCs with the exception of diethy phthalate and dibutyl phthalate. Phalates in the wine could be an issue of contamination from packaging [34].

Marquette wines made from grapes harvested at $22^{\circ}$ Brix had nine more aroma notes than grapes harvested at $24^{\circ}$ Brix. The most impactful compounds as determined by ADA were ethyl hexanoate and ethyl isobutyrate (both from $22^{\circ}$ Brix grapes); and ethyl decanoate and ethyl butyrate, both from $24^{\circ}$ Brix grapes. Published aroma descriptors for ethyl hexanoate are apple peel and fruit, sweet and rubber for ethyl isobutyrate, grape for ethyl decanoate, and apple for ethyl butyrate [35]. Frontenac wines made from both harvest points had six aroma notes each. The most impactful compounds as determined by ADA were ethyl hexanoate and ethyl octanoate (both from $22^{\circ}$ Brix grapes); and ethyl octanoate, ethyl decanoate, 1-pentanol, and ethyl isobutyrate from $24^{\circ}$ Brix grapes. Published aroma descriptors for ethyl octanoate are fruit and fat, balsamic for 1-pentanol [35]. An external calibration was used to quantify ethyl hexanoate, ethyl isobutyrate, and ethyl octanoate, and OAVs were calculated. The most impactful aroma compound with calculated $\mathrm{OAV}>50,000$ was ethyl isobutyrate contributes a fruity aroma.

A previous study reported $\beta$-damascenone, phenylethyl alcohol, acetic acid, linalool, and ethyl hexanoate quantified in Frontenac and Marquette grapes from veraision to harvest [9]. The compound ethyl hexanoate, responsible for fruity aromas increased in berry juice with increased growing degree days and differed by location in Pednault et al., 2013 [9]. In the wines in this study, no difference 
was found in ethyl hexanoate; however, these were taken from fruit with a greater level of ripening. However, $\beta$-damascenone, phenylethyl alcohol, acetic acid, and linalool are present in the wines from this study. Metabolic action of yeasts an influence wine aroma; specifically, precursors bound to glycosides or by decarboxylation of hydroxycinnamic acids to the equivalent vinylphenols [1]. Another study on Frontenac wine aroma reports 15 VOCs using a stir bar coated with PDMS [36]; 13 of these compounds were also detected in this study using headspace DVB/Carboxen/PDMS SPME. Similar VOCs detected were (from Table 2) compound numbers 12, 16, 19, 21, 22, 24, 27, 37, 39, 44, 46, 49, and 50. The optimized headspace SPME method yielded more compounds detected when compared to PDMS stir bar coated sample preparation method. In a previous study of commercial Frontenac wines, using a trained panel, aroma descriptors of the most impactful characters were black currant, cherry, and cooked vegetable [37]. These aromas correspond to methoxymethylbutanethiol or mercaptomethylpentanone (black currant) [35], and acrolein, butyrophenone, or cyclohexyl cinnamate (cherry) [38]. Other significant aromas in the sensory study included black berry, jammy, cooked vegetable, fresh green, cedar, floral, geranium, tamari, and earthy [37]. There is no consensus on the mechanism for explaining olfactory perception. Mixtures of odorants, even at concentrations below the detection thresholds, act in a synergistic manner [39]. This might be the key to understanding wine aroma, where hundreds of compounds are present.

A limitation to this study is the small sample size. Only one five-gallon vinification could be completed per treatment $\left(22^{\circ}\right.$ Brix and $24^{\circ}$ Brix) because only 12 vines were available. PCA analysis, in this study, only accounted for $48 \%$ of the variance between vinifications and is more reflective of the analytical method. More replications, repeated over several years would yield more data to draw direct conclusions about the aroma of Frontenac and Marquette wines. The olfactometry portions of this study allows for a single panelist at a time. The use of more panelists, $n>10$, could help account for variation within wine consumers due to age, sex, recognition and detection thresholds, etc.

This research adds to the growing body of knowledge about lesser-known wines from cold-hardy grapes grown in Midwest U.S. states. More research is needed to understand the aroma potential of these new cold-hardy grapes to produce quality wines that can stand on the same stage as traditional Old World wines. New cold-hardy grape cultivars that are complex hybrids of Vitis vinifera and native Vitis riparia have created a cold climate wine industry in North America. Frontenac and Marquette are vigorous, disease resistant and can grow sustainably in regions with low winter temperatures [30]. While there is significant information available for the aroma of $V$. vinifera wines, very little is known about the aroma profile of wines from cold-hardy grapes. Research is warranted to identify potential signature aromas in these new hybrid varieties as this information can advance viticultural practices, improve marketing and bolster the local economies of cold climate vineyards and wineries.

Supplementary Materials: The following are available online at http:/ /www.mdpi.com/2297-8739/5/1/20/s1.

Acknowledgments: This study was funded by the USDA's Specialty Crops Research Initiative Program of the National Institute for Food and Agriculture, Project \#2011-5118130850.

Author Contributions: S.R. and J.A.K. conceived and designed the experiments; N.L. and S.R. performed the experiments; S.R. analyzed the data; J.A.K., A.F. and M.D. contributed reagents/materials/analysis tools; and S.R., A.F., M.D., and J.A.K. wrote the paper.

Conflicts of Interest: The authors declare no conflict of interest. The funding sponsors had no role in the design of the study; in the collection, analyses, or interpretation of data; in the writing of the manuscript, and in the decision to publish the results.

\section{References}

1. Jackson, R.S. Wine Science Principles and Applications; Elsevier: Amsterdam, The Netherlands, 2008; ISBN 978-0-12-373646-8.

2. Sanchez-Palomo, E.; Diaz-Maroto, M.C.; Gonzalez-Vinas, M.A.; Soriano-Perez, A.; Perez-Coello, M.S. Aroma profile of wines from Albillo and Muscat grape varieties at different stages of ripening. Food Control 2005, 18, 398-403. [CrossRef] 
3. Bindon, K.; Varela, C.; Kennedy, J.; Holt, H.; Herderich, M. Relationships between harvest time and wine composition in Vitis vinifera L. cv. Cabernet Sauvignon 1. Grape and wine chemistry. Food Chem. 2013, 138, 1696-1705. [CrossRef] [PubMed]

4. Gomez-Miguez, M.J.; Gomez-Miguez, M.; Vicario, I.M.; Heredia, F.J. Assessment of colour and aroma in white wines vinifications: Effects of grape maturity and soil type. J. Food Eng. 2007, 79, 758-764. [CrossRef]

5. Vilanova, M.; Genisheva, Z.; Bescansa, L.; Masa, A.; Oliveira, J. Changes in free and bound fractions of aroma compounds of four Vitis Vinifera cultivars at the last ripening stages. Phytochemistry 2012, 74, 196-205. [CrossRef] [PubMed]

6. Yuan, F.; Qian, M. Quantification of selected aroma-active compounds in Pinot noir wines from different grape maturities. J. Agric. Food Chem. 2006, 54, 8567-8573. [CrossRef]

7. Yuan, F.; Qian, M.C. Aroma potential in early- and late- maturity Pinot noir grapes evaluated by aroma extract dilution analysis. J. Agric. Food Chem. 2016, 64, 443-450. [CrossRef] [PubMed]

8. Chang, E.; Jeong, S.; Hur, Y.; Koh, S.; Choi, I. Changes in volatile compounds in vitis labrusca 'Doonuri' grapes during stages of fruit development and in wine. Hortic. Environ. Biotechnol. 2015, 56, 137-144. [CrossRef]

9. Pedneault, K.; Dorais, M.; Angers, P. Flavor of cold-hardy grapes: Impact of berry maturity and environmental conditions. J. Agric. Food Chem. 2013, 64, 10418-10438. [CrossRef] [PubMed]

10. Slegers, A.; Angers, P.; Ouillet, E.; Truchon, T.; Pedneault, K. Volatile compounds from grape skin, juice and wine from five interspecific hybrid grape cultivars grown in Quebec (Canada) for wine production. Molecules 2015, 20, 10980-11016. [CrossRef] [PubMed]

11. Guillaumie, S.; Ilg, A.; Rety, S.; Brette, M.; Trossat-Magnin, C.; Decroocq, S.; Leon, C.; Keime, C.; Ye, T.; Baltenweck-Guyot, R.; et al. Genetic analysis of the biosynthesis of 2-methoxy-3-isobutylpyrazine, a major grape-derived aroma compound impacting wine quality. Plant Physiol. 2013, 162, 604-615. [CrossRef] [PubMed]

12. Lukic, I.; Radeka, S.; Grozaj, N.; Staver, M.; Persuric, D. Changes in physio-chemical and volatile aroma compound composition of Gewerztraminer wine as a result of late and ice harvest. Food Chem. 2016, 196, 1048-1057. [CrossRef] [PubMed]

13. Gametta, J.; Bastian, S.; Cozzolino, D.; Jeffery, D. Factors influencing the aroma composition of Chardonnay wines. J. Agric. Food Chem. 2014, 62, 6512-6534. [CrossRef] [PubMed]

14. Andrews, J.T.; Heymann, H.; Ellersieck, M. Sensory and chemical analysis of Missouri Seyval blank wines. Am. J. Enol. Vitic. 1990, 41, 116-120.

15. Canuti, V.; Conversano, M.; Calzi, M.L.; Heymann, H.; Mathews, M.A.; Eberle, S.E. Headspace solid-phase microextraction-gas chromatography-mass spectrometry for profiling the free volatile compounds in Cabernet Sauvignon grapes and wines. J. Chromatogr. A 2009, 1216, 3012-3022. [CrossRef] [PubMed]

16. Coelho, E.; Rocha, S.; Delgadillo, I.; Coimbra, M.A. Headspace-SPME applied to varietal volatile components evolution during Vitis vinifera L. cv. 'Baga' ripening. Anal. Chim. Acta 2006, 563, 204-214. [CrossRef]

17. Onuki, S.; Koziel, J.A.; Jenks, W.S.; Cai, L.; Rice, S.; van Leeuwen, J.H. Optimization of extraction parameters for quantification of fermentation volatile by-products in industrial ethanol with solid-phase microextraction and gas chromatography. J. Inst. Brew. 2016, 122, 102-109. [CrossRef]

18. Cai, L.; Rice, S.; Koziel, J.A.; Jenks, W.S.; van Leeuwen, J.H. Further purification of food-grade alcohol to make a congener-free product. J. Inst. Brew. 2016, 122, 84-92. [CrossRef]

19. Robinson, A.L.; Ebeler, S.E.; Heymann, H.; Boss, P.K.; Solomon, P.S.; Trengove, R.D. Interactions between wine volatile compounds and grape and wine matrix components influence aroma compound headspace partitioning. J. Agric. Food Chem. 2009, 11, 10313-10322. [CrossRef] [PubMed]

20. Pawliszyn, J. Solid phase microextraction in perspective. In Handbook of Solid Phase Microextraction; Pawliszyn, J., Ed.; Chemical Industry Press: Beijing, China, 2009; pp. 2-12. ISBN 978-7-122-04701-4.

21. Cai, L.; Rice, S.; Koziel, J.A.; Dharmadhikari, M. Development of an automated method for aroma analysis of red wines from cold-hardy grapes using simultaneous solid-phase microextraction-multidimensional gas chromatography-mass spectrometry-olfactometry. Separations 2017, 4, 24. [CrossRef]

22. Pavez, C.; Steinhaus, M.; Casaubon, G.; Schieberle, P.; Agosin, E. Identification, quantitation and sensory evaluation of methyl 2- and methyl 3- methylbutanoate in varietal red wines. Aust. J. Grape Wine Res. 2015, 21, 189-193. [CrossRef] 
23. Ferreira, V.; Ortin, N.; Escudero, A.; Lopez, R.; Cacho, J. Chemical characterization of the aroma of Grenache rose wines: Aroma extract dilution analysis, quantitative determination, and sensory reconstitution studies. J. Agric. Food Chem. 2002, 50, 4048-4054. [CrossRef] [PubMed]

24. Marti, M.P.; Mestres, M.; Sala, C.; Busto, O.; Guasch, J. Solid-phase microextraction and gas chromatography olfactometry analysis of successively diluted samples. A new approach of the aroma extract dilution analysis applied to the characterization of wine aroma. J. Agric. Food Chem. 2003, 51, 7861-7865. [CrossRef] [PubMed]

25. Bi, J.; Ennis, D.M. Sensory thresholds: Concepts and methods. J. Sens. Stud. 1998, 13, 133-148. [CrossRef]

26. Rice, S.; Koziel, J.A. Characterizing the smell of marijuana by odor impact of volatile compounds: An application of simultaneous chemical and sensory analysis. PLOS ONE 2015, 10. [CrossRef] [PubMed]

27. Rice, S.; Koziel, J.A. Odor impact of volatiles emitted from marijuana, cocaine, heroin and their surrogate scents. Data Br. 2015, 5, 653-706. [CrossRef] [PubMed]

28. Rice, S.; Koziel, J.A. The relationship between chemical concentration and odor activity value explains the inconsistency in making a comprehensive surrogate scent training tool representative of illicit drugs. Forensic Sci. Int. 2015, 257, 257-270. [CrossRef] [PubMed]

29. Rice, S.; Koziel, J.A.; Dharmadhikari, M.; Fennell, A. Evaluation of tannins and anthocyanins in Marquette, Frontenac, and St. Croix cold-hardy grape cultivars. Fermentation 2017, 3, 47. [CrossRef]

30. University of Minnesota, Minnesota Hardy. Available online: http://mnhardy.umn.edu/varieties/fruit/ grapes (accessed on 28 April 2016).

31. Chateau Stripmine, Frontenac Parentage. Available online: http://chateaustripmine.info/Parentage/ Frontenac.gif (accessed on 10 May 2017).

32. Chateau Stripmine, Marquette Parentage. Available online: http://chateaustripmine.info/Parentage/ Marquette.gif (accessed on 10 May 2017).

33. Leffingwell \& Associates. Odor \& Flavor Detection Thresholds in Water. Available online: http://www. leffingwell.com/odorthre.htm (accessed on 29 December 2017).

34. Chatonnet, P.; Boutou, S.; Plana, A. Contamination of wines and spirits by phthalates: Types of contaminants present, contamination sources and means of prevention. Food Addit. Contam. A 2014, 31, 1605-1615. [CrossRef] [PubMed]

35. Acree, T.; Arn, H. Flavornet and Human Odor Space. Available online: www.flavornet.org (accessed on 14 February 2018).

36. Mansfield, A.K.; Schirle-Keller, J.P.; Reineccius, G.A. Identification of odor-impact compounds in red table wines produced from Frontenac grapes. Am. J. Enol. Vitic. 2011, 62, 169-176. [CrossRef]

37. Mansfield, A.K.; Vickers, Z.M. Characterization of the aroma of red Frontenac table wines by descriptive analysis. Am. J. Enol. Vitic. 2009, 60, 435-441.

38. The Good Scents Company. Available online: www.thegoodscentscompany (accessed on 14 February 2018).

39. Patterson, M.Q.; Stevens, J.C.; Cain, W.S.; Cometto-Muniz, J.E. Detection thresholds for an olfactory mixture and its three constituent compounds. Chem. Sens. 1993, 18, 723-734. [CrossRef]

(C) 2018 by the authors. Licensee MDPI, Basel, Switzerland. This article is an open access article distributed under the terms and conditions of the Creative Commons Attribution (CC BY) license (http://creativecommons.org/licenses/by/4.0/). 